\title{
A CRITICAL DISCOURSE ANALYSIS OF DRUGS IN AMERICAN AND ARABIC NEWSPAPERS
}

\section{Prof. Dr. Qasim Obayes Al-Azzawi (Ph.D.) ${ }^{1}$ \\ Hussein Hamid Kareem}

${ }^{1}$ Department of English, College of Education for Human Sciences, University of Babylon

Email: dr.qasim_tofel@uobabylon.edu.iq

2 University of Babylon

\begin{abstract}
This study is concerned with investigating the term 'drug' as a general term for all the addictive materials that people use in their daily life. Such a thing is done through using critical discourse analysis perspective. This study is analysed according to Van Dijk's model entitled 'Discourse and manipulation'. The data is collected from American and Arabic newspapers reports. This study shows that the use of drug is considered as a very harmful habit that people resort to in order to achieve certain purposes. Unfortunately, using drugs results in very terrible outcomes represented by committing crimes or robberies. So, it is concluded that using drugs can affect society in the same way that terrorists might do since both result in horrible actions.
\end{abstract}

Key Words: CDA, drugs, newspapers, ideology, in-group , out-group, and manipulation. 


\section{Introduction}

This study is concerned with 'Drugs' and their horrible effects on the society. It shows how such a thing it dealt with the American and Arabic newspapers with highlighting the 'critical discourse analysis' as a major field in this study.

\section{Objective of the study}

This study is concerned with identifying the ways in which the American and Arabic newspapers deal with the concept of drug and its bad effect on society.

\section{Critical discourse analysis}

In the 1960s, a fascinating discipline arose that centered on the study of language use, the meanings speakers employ when interacting with one another, and the actions that come from using language in specific settings (Fairclough , 1995 ). It means that when dealing with language combinations such as phrases or sentences, discourse analysis ( DA ) does not have that specific limitation, but the utterance itself can be studied as a communicative action, such as "Tom is married" (Altschull, 1984).

The DA evolved over time, but there was a stage when it was heavily impacted by scholars of the modern period, particularly those of philosophy, sociology, and other subjects who contributed to the process of splitting linguistic analysis into different elements, primarily context, text, and society(Werlich, 1976). The growth of Critical Linguistics is aided by this process (Altschull, 1984). on the other hand, see the birth of Critical Discourse Analysis (CDA) as an practical method for identifying missing links, ideas, and procedures that may be used to determine what goals and principles are hidden beneath the text. CDA's development was a foreseen outcome of the CDA Group's efforts. Fairclough, Van Dijk, Wodak, and others formed the CDA Group in the 1980s to aid CL's transition to CDA. It's critical to demonstrate how CDA differs from DA in that it's transdisciplinary and problem-focused(Fairclough , 1995 ).

Because social relations are complicated and require a multi-methodological approach, it focuses on social relations rather than linguistic units analysis. As a result, a new method, CDA, was created and used to investigate discursive and social interactions (Schwarzmantel, 2008). Since the 1980s, CDA has been continuously developed over the previous thirty years. Later on, it was considered the most essential approach of linguistic analysis because it included not only language research but also context analysis. Psychologically, Van Dijk (2006) demonstrates that when speakers use language to communicate with one another, they create "mental models," which aid discourse cohesion. To put it another way, discourses play an important role in allowing and restricting speech and information. According to Bednarek (2006), language has a key role in imposing influence and controlling members' minds. As a result, the discourse is mainly used by the elite, such as leaders, scientists, legislators, and newspaper reporters(Blommaert, 2005).

Attitudes are different from ideologies in that they are adopted by a certain group of people. When it comes to immigration, for example, people have a wide range of opinions on whether it is good or bad, or whether it should be allowed or rejected (van Dijk, 2006). In truth, the term ideology is still vague, especially at the consciousness level (Fairclough, 1995). CDA views ideology as a critical component in dealing with 
power dynamics, which is why one of CDA's goals is to explain discourses by analyzing innate ideologies in order to inform people's actions(Blommaert, 2005).

In fact, language is influential because of the individuals who use it, therefore it cannot be regarded an aim in itself; rather, it aids in the transformation of power and compliance to either virtue or obligation. Multiple forms of language and power express this evident relationship between language and power (Blommaert, 2005).

Furthermore, Hayakawa (1978) demonstrates how powerful words can readily manipulate people's minds. When it comes to instructions and other forms of control used behind closed doors, this is well acknowledged. It is commonly recognized that powerful people take use of their position of power over other social classes, either through force or by assisting the weak class for certain goals(O'keeffe, 2006).

\section{Drugs}

Originally, the term "drugs" was applied to a wide range of medicines that numbed the senses and alleviated pain. Despite the fact that some people still refer to all drugs as "narcotics," the term "narcotic" now only refers to opium, opium derivatives, and semisynthetic replacements (Nehlig,2004). "Opioid" is a relatively recent word for these medications that has less ambiguity about its meaning. The illegal substance heroin, as well as medicinal medications such as OxyContin, Vicodin, codeine, morphine, methadone, and fentanyl, are examples(Magnusson, D, (1998).

Synthetic opioids, such as meperidine, fentanyl, and methadone, are manufactured wholly in a lab. Heroin, oxycodone, hydrocodone, and hydromorphone are semisynthetic opioids made from naturally occurring opium derivatives like morphine and codeine. Friends, family members, medicine cabinets, pharmacies, nursing homes, hospitals, hospices, doctors, and the Internet are all places where teens can get opioids (Salamone, 1992).

Drugs such as narcotics/opioids provide a general sensation of well-being through lowering tension, anxiety, and aggression, in addition to their medicinal usage. These effects are beneficial in a therapeutic setting, but they also contribute to the overuse of the medicines. Drowsiness, inability to concentrate, and apathy are only a few of the side effects of narcotic/opioid use (Nehlig,2004).

Psychological reliance on drugs is possible. The user may continue to think and talk about using drugs long after the actual desire for the drug has passed, and may feel overwhelmed coping with daily activities. If there are no adjustments to the physical surroundings or the behavioral motivators that led to the misuse in the first place, relapse is likely(Nehlig,2004).

The influence of drugs on a person's health is determined by various factors, including the person's current health status, stature, weight, sex, drug volume, method of drug consumption, length of abuse, concurrent use of alcohol or other drugs, and the presence of an underlying psychiatric disorder(Magnusson, D, (1998). Even shortterm heroin use has negative consequences for one's health. Although the most prevalent adverse effects of heroin usage are transient and pass, they always pose an unwarranted risk to one's health (Salamone, 1992). 
Because the body has become accustomed to the presence of the drug, withdrawal symptoms will occur if the usual amount of use is reduced or stopped entirely. Vomiting, muscle discomfort, restlessness, and drug cravings are all common withdrawal symptoms. Physical dependence might develop into a clinical condition of addiction over time (Salamone, 1992).Furthermore, research suggests that heroin misuse can cause a degeneration of the white matter in the brain, which can have a direct impact on decision-making abilities, behavior control, and stress-response mechanisms. Changes in the brain can also make it more likely to relapse. According to research, those who have a history of heroin misuse are more likely to relapse after establishing recovery than people who have never abused heroin (Matheson, 2005). Drugs don't mean to have heroin only, but also some other social activities might have the same symptoms as those of drugs. Using social media excessively results in social deterioration and isolation (Nehlig,2004). Such a thing has a very bad effect on the person's health and social relations as well. Those addicted figures on social media find peace with such apps. Once they are separated , users get angry and lose the usual behaviour (Salamone, 1992).

\section{Newspapers}

Reading a newspaper keeps one up to date on current events and news throughout the world. Newspapers can also keep you informed about what's going on in your community. Reading newspapers allows one to learn and learn about a variety of topics, not just those that have occurred in the past, but also those that are likely to occur. As a result, it has been observed that newspapers are more easily learned from than news because they are available anywhere and at any time. Newspapers, in fact, provided a wide range of news, such as weather forecasts, various reports from various locations, business information, and so forth (Jucker, 2007). A newspaper is not only a source of information, but also a source of entertainment. As a result, newspapers can be seen of as more up to date, conveniently accessible, and a beneficial tool in the research process (Blommaert, 2005).

Jaworski, A. \& Coupland, N. (1999) show that newspapers have undergone significant changes throughout history, owing to a variety of factors such as political, social, and economic factors. From the commencement of newspaper publication, authors have attempted to produce reports in a way that meets the needs of the readers. As a result, newspapers have always attempted to print news that appeals to readers' preferences (Conboy, 2010). Newspapers have been around for a long time. People used to get information from gatherings among groups or through word of mouth (Breeze, 2011).

The importance of news cannot be overstated. Bell (1991) acknowledges that news is an important aspect of a newspaper because news is the most requested page by readers in every day newspapers. He asserts that news must have values, and that news must be ordered. The value of news is easily influenced by the type of language used by the writer, because the content of the news will vary as a result of the change in language. Breeze (2011).demonstrates that news has particular values, and these values determine the news' quality. Several things influence this, including prominence, effect, conflict, tome, and so on(Elkartea, 2010). 
According to Breeze (2011).the function of the newspaper is to discover new facts about topics that readers are interested in. Newspapers can also express opinions, make remarks, state facts, and do a variety of other tasks. Introducing extraordinary news, on the other hand, is the criterion by which people assess the news' worth.

Newspapers were geared to the general public, as they are now, for a variety of reasons, and readers expect to deal with fresh news from various locations in diverse ways (Blommaert, 2005)..Written notes have been used to communicate news throughout history, including in Ancient Rome, where they were known as Acta Diurna (Daily Events) to deliver news, particularly those relating to social and political events (Breeze, 2011).

People in general enjoy reading, however there are certain distinctions to be noticed. Newspapers are the thicker periodicals that include a lot of information for readers to read. People can find a variety of sources in newspapers that they enjoy, including weather forecasts, posters, business possibilities, political and financial news, and so on (Dahl, 1957).

The language of newspapers was substantially influenced by technologies in the twentieth century, as they began to compete with newspapers as the sole and most acceptable source of information around the world(Crystal, 2008).

The term 'newspaper' denotes that the content of a newspaper is mostly comprised of news and editorial commentary on the news. A newspaper, on the other hand, contains a variety of materials such as images, ads, news analysis, games, and the like. Despite the fact that newspapers cover a wide range of topics, some are dedicated to specific topics other than news. For example, some people are especially interested in celebrities, television personalities, or even the activities of a certain assembly or family, such as the kingly family( Cotter, 2010).

\section{Methodology}

This section introduces the research approach used in the current study. It demonstrates how the study is set up and how the data is gathered.

\subsection{Data collection}

The study examines four reports from two separate newspapers, one American and the other is Arabic to ensure consistency. The American newspaper is Washington Post and the Arabic newspaper is Al-Hayat. These reports were selected from these newspapers on the internet from 2015 to 2021 to ensure updated data. They are beneficial in creating a clear picture of drugs in these two newspapers. They figure out people's differing viewpoints regarding how drugs are viewed from various perspectives. Choosing multiple newspapers also aids in the discovery of actual and true facts, demonstrating the parallels and variations between media reporting of such a heinous material.

\subsection{Model of the study}

This study is based on Van Dijk's Socio-cognitive model entitled "discourse and manipulation" ( 2006 ). This approach was adopted to aid in the analysis of media reports by dividing them into two groups: the positive in-group and the negative out- 
group. Ordinary people, victims, and official members all make up the positive ingroup. The drug and heroin addicts in general reflect the negative out-group. Van Dijk employed a number of ways to accomplish this research, which are detailed in the publications. These tactics or strategies are listed as below:

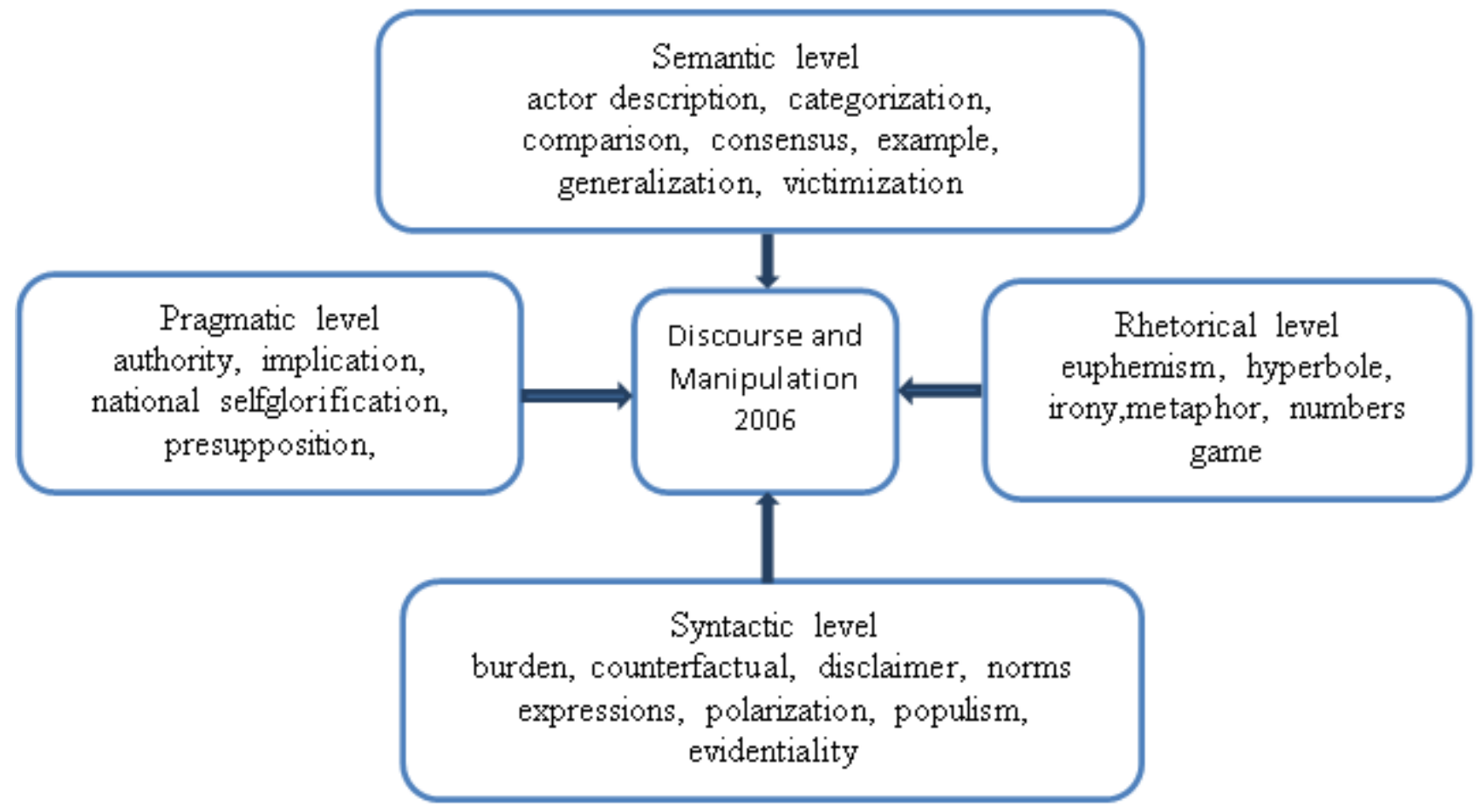

\subsection{Data analysis}

The data is gathered or collected from two different newspapers. The first newspaper is the American one and the second newspaper is the Arabic one.

\subsubsection{Data of the American newspaper}

Two reports are considered to be as the data to be analyzed collected from The Washington Post newspaper.

\section{First Report: "Maryland launches initial plans to fight heroin epidemic" By Josh Hicks August 25, 2015}

From the very beginning, the reporter uses the norm expression strategy to describe the process of preventing drugs as a war "to fight heroin epidemic". This thing was intentionally used by the writer in order to convey the idea that drugs have a bad effect on society in general, and this indicates the use of another strategy represented in implication, where the writer implies that the uses of drugs in society must be eliminated in order to keep everyone safe from this wrong and dangerous use which was described as epidemic.

The reporter uses another strategy, which is the authority strategy accompanied with evidentiality represented by the law enforcement "boost law enforcement efforts to disrupt dealers and launch a public-awareness campaign about the dangers of addiction", where he shows that the role of the state and the law forces is to strive to prevent the availability of drugs among members of society, and this requires a great and consistent effort between individuals in order to eliminate this situation, which 
requires awareness from the community in order to start campaigns to direct about the dangers of drugs which may lead to death, as drug use is one of the main causes of death.

Elimination of drugs may require the availability of efforts with the necessary financial capabilities, as the reporter uses the number strategy in order to document the clear link between the reality represented in the existence of drugs and the truth of the report, to achieve objectivity, as it refers to the existence of financial campaigns carried out by governments or individuals in order to combat drugs and reform addicts "The state will spend \$2 million in already approved funds on various initiatives" and this thing is considered as one of the strategies used by the reporter in order to distinguish between the dangers represented in the use of drugs on the one hand and the dangers that civilians face on the other hand, and this thing creates for us two fronts represented in the in-group and the out-group.

The reporter uses another strategy represented in the use of consensus which shows a kind of agreement among the in-group members to affirm a certain fact. The use of drugs may affect the individual in a significant way, as it leads to a physical and mental imbalance for the individuals, and this would result in many negative aspects. Helping addicts get rid of this bad and deadly habit at the same time requires the establishment of training centers to draw the attention of readers to the dangers of addiction in general "expanded training in how to administer drugs that can reverse the effects of an overdose". Thus, training is considered as a crucial need in order to help those who use drugs.

The reporter warns through writing this report that drug addiction may end in tragic ends, which is death, and this was used by the writer on purpose in order to warn readers of the dangers of using heroin. This thing represents burden strategy that the writer has followed in attracting the readers' attention and for the purpose of indicating the objectivity of the report.

The reporter uses many different strategies, as the writer uses the strategy of national glorification, which is to defend the bad use of drugs by individuals, as the writer uses another strategy, which is the strategy of presupposition, where the writer assumes that the battle against addiction may take a long time to fight it and eliminating them "This is going to be a long-term struggle to turn back the tide". This is considered a kind of vagueness strategy that the reporter resorts to in the absence of accurate information despite it is being taken from individuals in official ranks.

The reporter returns to the use of the strategy of authority, which is represented in the government's efforts by the police stations to raid gangs that distribute drugs among members of society. This requires a long time and great financial capabilities in order to identify the distributors of drugs in the community, where efforts are required to identify the vehicles that transport drugs transporting them from one place to another and seized "The state will also provide more money to police departments to disrupt gangs that distribute heroin. The funding will go toward overtime ... can help identify traffickers traveling". Such a thing indicates the use of the strategy of comparison. Here, the reporter makes a distinction between the in-group officers against the outgroup drugs distributers. 
Second Report: "Cocaine overdose deaths jump in recent years, CDC reports" By Linda Searing October 11, 2020

The writer, from the beginning of the report and its title, uses the strategy of norm expression, as it indicates that the doses used by addicts have increased in recent years, and this represents a kind of real addiction that exists among members of society "Cocaine overdose deaths jump in recent years". The presence of drugs in abundance among individuals, and this represents a kind of complacency on the part of the authorities or the weakness of the state, due to the spread of drugs and excessive doses that lead to the sad end which is death.

In this report, the reporter uses many strategies in order to clarify the difference between the two groups, the in- group that of innocent civilians and the second outgroup that represents addicts, as the writer uses the numbers strategy in order to clarify the difference between the previous cases of addiction and the later cases where the number of doses that the addicts take is increased among the members of society. Moreover, the reporter uses other strategies represented in the strategy of euphemism. This strategy represents the reduction of many bad things, as although the end is aways in death, but he uses numbers instead of mentioning the number of deaths that have increased and this a kind of irony strategy where the reporter mentions the number of doses without mentioning the increased number of the deaths.

The reporter uses the comparison strategy, where he makes a comparison between the years in order to convey a specific idea. The comparison is between 2009 and 2018, where the reporter explains a significant increase in the extent of the doses taken by addicts, which shows the society's excessive use of drugs "The rate of overdose deaths remained stable from 2009 through 2013, the report found, but then headed upward at about 27 percent each year from 2013 through 2018”. This will lead to tragic results that end in social poverty, family disintegration, as well as lack of social awareness.

The reporter uses the strategy of the authority in order to explain the reasons for the spread of drugs among members of society. The reporter points out that one of the reasons for the spread of drugs is that they are constantly being cultivated with permission in some areas and exported to the rest of the peoples. The report, which is based on the strategy of the authority, blames Colombia and ends with it, accusing it of being the main source of drug cultivation and exportion to members of the community "cultivation and cocaine production in Colombia". These phrases used by some local authorities represent a kind of strategy that is followed in newspapers reports, where this strategy is called counterfactual. It shows a kind of cause and effect, which means that the reason for the spread of drugs in the world is Colombia's cultivation of it and its export around the world to spread widely among young people.

The reporter relies on the strategy of authority in order to convey a certain idea, which is the spread of drugs between certain classes and individuals, as the writer uses another strategy represented in the norm expression. This thing shows the difference between men and women in their use of drugs. This report shows that men use drugs more often than women, and drug use is more common among middle-aged individuals "cocaine was higher among men than women and more common among middle-aged people". 
In this report, the reporter combines additional strategies, including ambiguity, where he explains the spread of drugs between certain classes without others without clarifying the reason. Drugs can be found within the same country, but it may vary from one region to another. It was used a lot in urban areas, but it is less used in regions in rural areas. The reporter uses the comparison strategy where he explains that there are two classes in society, represented in the class that uses drugs lives in urban areas, and the class that does not use drugs lives in rural areas "those living in urban rather than rural areas".

Once again, the reporter uses the strategy of norm expression as a normal description for the events covered by the newspapers reports. The reporter explains that drugs have a negative and bad effect on the health of the individual in society, as it leads to breathing problems as well as high blood pressure with some hallucinations that occur and may lead to heart attacks or a case of mental anomalies "overdoses can cause breathing problems, high blood pressure, hallucinations and extreme agitation, as well as seizures, heart attacks and strokes". This thing was explained by the strategy of evidentiality, as it is considered as an epidemic spreading in society, and the appropriate treatment should be found to eliminate it in order to preserve people's lives. Using drugs is not less dangerous than wars that result in the destruction of peoples' lives

\subsubsection{Data of the Arabic newspaper}

The Arabic newspaper is Al-Hayat. It is one of the prominent Arabic newspapers. Two reports will be chosen to be analysed.

\section{First Report: “19,000 kg of banned drugs, 81,000 liters of liquor seized by Saudi customs authorities in first half of 2021" August 19, 2021}

The Arabic newspapers have a very important coverage on the events that revolve around the use of drugs. Since the beginning of the title of the newspaper report, the reporter has used a number of strategies to attract the attention of the reader. One of these strategies is norm expression of the events accompanied with the strategy of number game, and this thing was intentionally used by the reporter on order to achieve objectivity. The use of the drug is prohibited by the Saudi authorities who arrested drug smugglers, as they tried to smuggle about 19,000 kilograms of drugs in the current year "19,000 kg of banned drugs".

In addition to that, the reporter uses another strategy represented in the strategy of the authority, through which he clarified the official attempts practiced by the law in order to prevent the use of drugs inside the Kingdom of Saudi Arabia, where he clarifies that there are approximately 1,000 attempts that have been thwarted, and this thing may create a kind of security imbalance inside the Kingdom. The use of numbers and terminology of the authority is for the purpose of distinguishing between the drug class and the class of civilians who suffer from the risk of drug spread among members of society "Saudi authorities have thwarted more than 1,000 attempts to smuggle prohibited items into the Kingdom".

The reporter uses another strategy, which is the strategy of categorization, where he distinguishes types of drugs that some may resort to for the purposes of distributing 
them among members of society. Where the reporter explained that there are more than 126 million types of tranquilizer capsules, as well as which are divided according to certain types such as hashisha, drugs and cocaine, in addition to more than 60,000 boxes of wine and other legally prohibited liquids. This thing shows the way the reporter deals with the report. He gives detailed information that indicates the credibility of the newspaper report, and this thus affects the ideology of the individual.

In order to secure the country from the danger of drug spread among members of society, the local authorities take a number of security measures. In this area, the reporter mentions through the evidentiality strategy because the local authorities carried out awareness campaigns as well as inspection campaigns in various areas, starting with the customs areas, which is one of the main entrances to the country that through which goods enter "The Authority processed more than 39 million tons of goods coming to the Kingdom with a total value of more than SR302 billion". The authorities carefully searched these areas including various places such as customs, vehicles and goods.

The reporter uses another strategy represented in the use of counterfactual to explain that due to the spread of drugs among members of the community, the local authorities have increased the customs duties taxes imposed on goods entering the country in order to reduce the spread of the drug. This thing created a state of imbalance due to the sudden rise in prices, which greatly affected the individual economy. That led to the weakness of the spread of drugs due to the weakness of financial ability "the authority received more than 580,000 tax and zakat declarations from all business officials subject to tax regulations".

Another strategy that the reporter uses in this report in abundance is the strategy of numbers game "detecting more than 20,000 zakat and tax violations and answering about 9,000 communications". It is one of the important strategies for the purpose of publishing a report in an objective manner because it has a significant impact on the credibility of the report and therefore this report greatly affects the mind of the reader. So, this reporter uses this strategy in order to focus on the actions carried out by the local authorities in order to reduce the spread of the phenomenon of drug use among members of society, as well as to distinguish between local authorities as the safe side of society and the side of people who take drugs as being a danger to society and this must be healed in different and multiple ways.

In order to address the situation of drug spread among individuals, it is necessary to use some appropriate methods. In this regard, the reporter uses strategies of national glorification in order to focus attention on the procedures that the government follows in order to address this situation. Some government procedures are represented in different ways, including holding seminars among families as well as seminars in order to focus on the spread of this deadly epidemic, activating control committees with a focus on the country's entrances in order to prevent the spread or entry of these drugs of all kinds, directing addicts to the right direction and holding them legally so that there is no transgression in the future " it held some 60 workshops targeting individuals, interested people and taxpayers". 
Second Report: "EU report: illicit drugs sale moved online during the lockdown" June 09, 2021

The reporter uses the presupposition strategy where he explains that due to the spread of the Corona epidemic around the world and due to the closure policies adopted by some countries around the world, the spread of drugs has taken place through the Internet "illegal drug production increased during corona epidemic". Distributors have sent messages through social media in order to increase the distribution of drugs and this thing may It spread very quickly due to the health crisis that accompanied the period of international closure, which gave way to an increase in the drug trade, which did not result in an increase in the number of addicts.

Because of the closure policy that countries have followed, drug promoters have found an open room to move from one place to another because of the avoidance of contact. During the international ban, due to staying away from contact with individuals and avoiding inspection "relying less on human courier", and that led to the spread of drugs among individuals, and it gave way to an increase in the negatives of drugs and a decline in international mobile measures to prevent them. So the reporter explains, through the strategy of implication, that drugs increase when there is a decline in security measures, and this is what one can notice during the period of the spread of the epidemic. This thing led to an increase in the percentage of individuals in the purchase of drugs.

The consensus strategy is one of the other strategies that the reporter uses to describe the events that revolve around drugs, as he explains that the spread of drugs is based on an agreement between the seller and the buyer during the period of the spread of the Corona epidemic. The spread of drugs was done by sending messages through social media between the seller and the buyer, and then the drugs were delivered through the delivery service " media platform for negotiating purchases and to home delivery services for distribution". Therefore, the Corona epidemic period may be considered one of the essential periods for drug sellers and promoters, as it achieved great profits and wide spread in very few periods away from the legal environment. So, though there is an epidemic among individuals, there is another epidemic beneath represented, through the strategy of irony, by the use of drugs.

The reporter uses the strategy of hyperbole in order to describe the use of drugs among members of society and its spread that is done very quickly. The reporter explains that these drugs have spread among homes, among individuals as well as across borders during the period of the international ban during of the Corona epidemic. This thing resulted in its spread globally without the presence of any restrictions that limit their movement and thus have become another global epidemic that threatens human existence and health in a horrible way "risking the health and security of our citizens". This strategy has been used by the reporter in order to draw the attention of readers to the side effects of drugs and their spread at anytime and anywhere, especially that it does not require a large place to be kept in. They can't be discovered easily and they can be exported in different quantities, in different sizes, and in different ways. Then, they will be received and distributed among individuals in other countries. 
Finally, the reporter resorts to using the numbers game strategy in order to clarify that there is an excessive increase in the use of drugs, especially after the period of the global epidemic, and this led to an increased risk to human health. It is discovered by specialists, where many notice, there is a very big difference between the previous years and the years of the epidemic in the sense that this epidemic has facilitated its spread in a way, which led to an increase in the dangers of drugs among individuals, especially young people.

\section{Results}

\begin{tabular}{|l|l|l|l|}
\hline American report 1 & American report 2 & $\begin{array}{l}\text { Arabic report } \\
1\end{array}$ & $\begin{array}{l}\text { Arabic report } \\
2\end{array}$ \\
\hline 1. norm expression & 1. norm expression & 1. authority & 1. presupposition \\
\hline 2. implication & 2. number & 2. norm expression & 2. implication \\
\hline 3. authority & 3. euphemism & 3. categorization & 3. consensus \\
\hline 4. evidentiality & 4. irony & 4. evidentiality & 4. irony \\
\hline 5. number & 5. comparison & 5. counterfactual & 5. hyperbole \\
\hline 6. consensus & 6. authority & 6. numbers game & 6. number game \\
\hline 7. burden & 7. counterfactual & $\begin{array}{l}\text { 7. national } \\
\text { glorification }\end{array}$ & \\
\hline $\begin{array}{l}\text { 8. national } \\
\text { glorification }\end{array}$ & 8. norm expression & & \\
\hline & 9. ambiguity & & \\
\hline
\end{tabular}

Fig.1 Distribution of Strategies in American and Arabic Newspapers

After the analysis of the data and examining the number of the strategies used in both newspapers, it can be clear that there are differences found between these two languages. The American languages tend to use more discursive strategies so that the message will have lore dominant role. It has a more convincing effect. It means that the American newspapers manipulate the news published indirectly to achieve certain goals. They have more advanced system of writing in which news published in a very profound way.

The Arabic newspapers use a number of strategies, but not similar to that of the American ones. It means the Arabic newspapers tend to use a few number of strategies in publishing the news. Such a thing will have an influence, but in a more limited way since using more strategies give more spirit to the reports. 


\section{Conclusion}

After dealing with the analysis of the data, there are certain points to be discussed. On the one hand, American newspapers provide more information through various techniques and philosophies. These publications have a habit of linguistically transmitting news by focusing excessively on drugs and paying little attention to the victims. These publications use ideological language intended at weakening security and stability in nations where drug abuse is rampant. This could indicate the target countries' weaknesses, allowing the countries supporting these journals to achieve their political goals.

Linguistic prejudice is a prominent aspect of American newspapers, in which these newspapers utilize language that do not correspond to the crimes committed by drug users, such as soft-spoken vocabulary. Furthermore, American newspapers emphasize the terror that drug usage fosters in these countries, and hence place a strong emphasis on the utilization of drug manufacturing procedures. This is a negative portrayal that detracts from the objectivity of the reports provided in these newspapers.

When compared to American newspapers, Arabic newspapers provide fewer details and employ fewer methods and ideologies. This could imply conveying the truth about the drugs incident without the use of media intimidation by showing addiction realistically. Through the use of linguistic terms aimed at preserving the balance of news that catches the reader's attention, Arabic newspapers focus not just on consuming drugs, but also on other elements, including victims and the effects of addiction incident honestly and truthfully.

As a result, such an action maintains the target countries' optimistic mood and gives people optimism that they will be able to conquer drug usage and eliminate it once and for all. This indicates that these newspapers have more flexibility than newspapers in the United States.

Furthermore, the objective explanation may be eminent by the use of non-biased linguistic terms, such as calamity, extermination, or labeling the drugs user as an assassin, a terrorist, or a ruthless killer, or by using terminology that conforms to the use of drugs crimes, such as disaster, massacre, etc. As a result, one can observe that Arabic publications do not solely focus on drug manufacturing procedures, but also on other issues such as security leaders and victims. The fact that the press covers drug usage in a variety of ways supports the premise of an impartial transfer of Arabic publications. 


\section{Reference}

Altschull, J.(1984). Agents of power. New York and London. Longman.

Bednarek, M.(2006). Evaluation in media discourse: analysis of newspaper corpus.

Blommaert, J. (2005). Discourse: A Critical introduction. Cambridge: Cambridge

Breeze, R. (2011). "Critical discourse analysis and its critics". Journal of Pragmatics. Continuum New York. London.

Cotter, C. (2010). News talk: investigating the language of journalism. Cambridge

Crystal, D. (2008). A dictionary of linguistics and phonetics. Oxford: Blackwell.

Dahl, R. (1957)."The concept of power". behavioural science. 2.3: 201-2014.

discourse analysis approach to the analysis of a newspaper article. MA thesis. discourse analysis. Annual Review of Applied Linguistics. Edinburgh.

Elkartea, G. (2010). The Press and the media. Spain. Gipuzkoa.

Fairclough, N..(1995). Critical discourse analysis: the critical study of language. London: 17, No.2: 359-83. London: Sage. https://pdfs.semanticscholar.org. [Accessed in 621.4: 493-525. Web. 6 Nov. 2016. introduction. Los Angeles: Sage Publications.

Jaworski, A. \& Coupland, N. (1999). (eds.) . The Discourse reader. London: Routledge.

Jucker,A. (2007). Early modern English news discourse. Amsterdam. John Benjamins

Luke, A. (2002). Beyond science and ideology critique: developments in critical discourse analysis. Annual Review of Applied Linguistics.

Magnusson, D, (1998). Theoretical Models of Human development. New York: John Wiley \& sons. pp. 685-759.

Matheson, D.(2005). Media discourse : Analysing media Text. London. Open University

Nehlig A (2004). Coffee, tea, chocolate, and the brain. Boca Raton: CRC Press. pp. 203-218. ISBN 9780429211928.

Nunan, David.(1993). Introducing discourse analysis. New York: Penguin Books.

O'keeffe, A.(2006). Investigating media discourse. London and New York. Routledge Press.Publishing Company. Sage Publications.

Salamone JD (1992). "Complex motor and sensorimotor functions of striatal and accumbens dopamine: involvement in instrumental behavior processes". Psychopharmacology. 107 (2-3): 160

74. doi:10.1007/bf02245133. PMID 1615120. S2CID 30545845.

Schwarzmantel, J. (2008). Ideology and politics (2nd ed.). London: Sage Publications. University of Leicester. 
Van Dijk, T. (2006). "Discourse and manipulation". In Discourse and Society. Vol. 17, No.2: 359-83. London: Sage. https://pdfs.semanticscholar.org. [Accessed in 6 May,2017].

Werlich, E.(1976). A text grammar of English. Heidelberg.Quelle \& Meyer. 